\title{
A evolução do Ideb nos anos iniciais do ensino fundamental nos municípios capixabas (2007-2017): uma análise com foco em Presidente Kennedy
}

The evolution of the Ideb in the early years of elementary education in the cities of Espirito Santo

(2007-2017): an analysis with a focus on President Kennedy

\begin{abstract}
Resumo: Este artigo tem o objetivo de analisar a evolução do Ideb nos anos iniciais do ensino fundamental $\left(1^{\circ}\right.$ ao $5^{\circ}$ anos) nos municípios capixabas, no período 2007-2017, com foco em Presidente Kennedy. Adotando como metodologia uma investigação exploratória estatística com base nos microdados do Inep, a pesquisa também buscou identificar as causas do declínio do desempenho do referido município. Os resultados apontam que parte dessa queda de desempenho pode ser explicada pela redução da participação dos estudantes na Prova Brasil em 2015. Por outro lado, mesmo com cerca de $70 \%$ de alunos a mais participando da Prova Brasil em 2017, Presidente Kennedy obteve, naquele ano, Ideb superior ao de quatro anos antes. Nesse caso, pelo menos três variáveis podem ajudar a explicar a melhoria relativa do desempenho do município: gasto público por aluno acima da média; infraestrutura e recursos pedagógicos adequados; e melhoria da remuneração e da qualificação dos professores.
\end{abstract}

Palavras-Chave: Ideb. Anos iniciais do ensino fundamental. Presidente Kennedy.

\begin{abstract}
This article analyzes the evolution of Ideb in the early years of elementary education in the cities of the state of Espirito Santo, in the period 2007-2017, with a focus on Presidente Kennedy. Adopting statistics based on microdata from Inep as methodology, this study sought to identify the causes of the decline of the performance of President Kennedy. The results indicate that this drop in performance can be explained by the reduced participation of its students in the Prova Brasil in 2015. Even with approximately $70 \%$ of students more taking the exam, the city obtained, in this last year, Ideb superior to four years before. In this case, three variables can help explain the relative improvement of the overall performance of Presidente Kennedy in the Ideb: public spending per student above average, provision of adequate infrastructure and pedagogical resources and improvement of remuneration and the qualification of teachers.
\end{abstract}

Keywords: Ideb. Early Years of Elementary School. Presidente Kennedy municipality.

\author{
Hilda Angélica L. Fontana Gomes \\ Hilda Angélica L. Fontana Gomes \\ Mestranda em Ciência, Tecnologia e Educação, pela Faculdade Vale do Cricaré (FVC). \\ Professora da rede municipal de educação de Presidente Kennedy (ES). E-mail: hildaangelicafg@gmail.com
}

Thaís Cardoso Guimarães de Aguiar

Mestranda em Ciência, Tecnologia e Educação, pela Faculdade Vale do Cricaré (FVC).

Professora da rede municipal de educação de Presidente Kennedy (ES). E-mail: thaiscga@hotmail.com

\author{
Luana Frigulha Guisso \\ Doutoranda em História Social das Relações Políticas, pela Universidade Federal do Espírito Santo (UFES). \\ Coordenadora adjunta e professora do Mestrado Profissional em Ciência, Tecnologia e Educação da Faculdade \\ Vale do Cricaré (FVC). E-mail: Ifgd10@hotmail.com
}




\section{Introdução}

Criado em 2007 pelo Instituto Nacional de Estudos e Pesquisas Educacionais Anísio Teixeira (Inep), o Índice de Desenvolvimento da Educação Básica (Ideb) é um indicador global sintético, que combina dados de desempenho em exames padronizados [Prova Brasil ou Sistema de Avaliação da Educação Básica (Saeb)] - obtidos pelos estudantes ao final das etapas de ensino $\left(5^{\circ}\right.$ e $9^{\circ}$ anos do ensino fundamental e $3^{\mathrm{a}}$ série do ensino médio) - com informações sobre rendimento escolar (taxas de aprovação, reprovação e abandono apuradas no Censo Escolar) ${ }^{2}$. Ainda que a complementaridade entre o desempenho dos estudantes em exames e o rendimento escolar seja evidente, os estudos e as análises sobre a qualidade educacional raramente combinam essas duas informações, tornando o Ideb um indicador diferenciado e de importância singular.

Formulado para medir a qualidade da aprendizagem no País e estabelecer metas para a melhoria da educação, com o passar do tempo, o Ideb foi sendo associado a indicador de qualidade da educação básica brasileira, ganhando grande força política. Para escolas e municípios, são utilizadas as médias de desempenho da Prova Brasil; para os estados e o País, são considerados os resultados do Saeb. As metas estabelecidas pelo Ideb são diferenciadas para cada escola e para cada rede de ensino com 0 objetivo de alcançar 6,0 pontos até 2022.

No contexto do estado do Espírito Santo, destaca-se a evolução do Ideb apresentada por Presidente Kennedy, que alcançou, em 2015, a $5^{a}$ posição entre os 78 municípios capixabas, graças à transferếncia à educação municipal de parte significativa da arrecadação de royalties e participações especiais do petróleo da Bacia de Campos explorado em seu litoral marítimo, que atingiu um total de $\mathrm{R} \$$ 187.798.015,93 a preços correntes naquele $a^{3}{ }^{3}$ (INFO ROYALTIES, 2020).

1 A Prova Brasil, na verdade, Avaliação Nacional do Rendimento Escolar (Anresc), é aplicada censitariamente a alunos do $5^{\circ}$ e do $9^{\circ}$ anos do ensino fundamental, exclusivamente das escolas públicas, com, no mínimo, 20 alunos matriculados nas séries avaliadas. 0 Saeb, por sua vez, corresponde à Avaliação Nacional da Educação Básica (Aneb) e é aplicado a uma amostra de estudantes das redes pública e privada, matriculados no $5^{\circ}$ e no $9^{\circ}$ anos do ensino fundamental e no $3^{\circ}$ ano do ensino médio.

2 Para maiores detalhes sobre a definição, construção e cálculo do Ideb, consultar a publicação Índice de Desenvolvimento da Educação Básica (Ideb), na Série Documental - Texto para Discussão $n^{0} 26$, disponível em: $<$ www.inep.gov.br>

3 Os limites deste artigo não tornarão possível o detalhamento da arrecadação orçamentária dos municípios capixabas, de modo especial Presidente Kennedy. Diante disso, sugere-se a consulta ao Info Royalties (2020).
Assim, considerando a relevância do Ideb para as escolas e as redes de ensino, tomando como referência o desempenho do município capixaba de Presidente Kennedy e partindo dos desdobramentos da pesquisa de dissertação intitulada "Avaliação na aprendizagem da Educação Infantil: um estudo de caso no município de Presidente Kennedy-ES", desenvolvida no Mestrado Profissional em Ciência, Tecnologia e Educação, da Faculdade Vale do Cricaré (FVC), será apresentada, neste artigo, uma análise da evolução do Ideb nos anos iniciais do ensino fundamental nos 78 municípios capixabas, entre 2007 e 2017, com foco em Presidente Kennedy. 0 objetivo é o de proceder a uma investigação exploratória das causas da perda de desempenho do município entre 2015 e 2017.

Estruturado em quatro seções, o artigo apresenta, nesta primeira seção, a introdução da problemática abordada. $\mathrm{Na}$ segunda seção, analisa a evolução do Ideb nos anos iniciais do ensino fundamental nos 78 municípios capixabas, entre 2007 e 2017. Na terceira seção, destaca 0 desempenho de Presidente Kennedy e, na quarta seção, finaliza com as considerações finais.

\section{A evolução do Ideb nos anos iniciais do ensino fundamental nos municípios capixabas (2007-2017)}

Ao se analisar o período 2007-2017, observa-se que todos os municípios capixabas apresentaram trajetória crescente no Ideb nos Anos Iniciais do Ensino Fundamental. Neste conjunto, destacam-se particularmente Mantenópolis $(+0,76 \%)$, Água Doce do Norte $(+0,65 \%)$, Pedro Canário $(+0,54 \%)$, Presidente Kennedy $(+0,51 \%)$, Ecoporanga $(+0,49 \%)$, Barra de São Francisco (+0,48\%), Atílio Vivacqua $(+0,47 \%)$, Itapemirim $(+0,47 \%)$, Anchieta $(+0,46)$, Águia Branca $(+0,45)$ - que também apresentou 0 maior Ideb do estado em $2017(6,8)$-, Alegre $(+0,45)$ e Mimoso do Sul $(+0,45)$, que apresentaram, respectivamente, as 12 maiores evoluções percentuais, bem acima dos $+0,33 \%$ do estado.

Geograficamente, estes 12 municípios estão distribuídos quase exclusivamente pelo sul do Espírito Santo, que concentra metade deles (Atílio, Anchieta, Alegre, Itapemirim e Mimoso e Kennedy, que fazem divisa com o Rio de Janeiro), e pelo noroeste do estado, onde se situam cinco (Águia Branca, o único que não faz divisa com Minas Gerais, Água Doce do Norte, Mantenópolis, Ecoporanga e Barra de São Francisco), sendo a única exceção Pedro Canário, que faz divisa com a Bahia, no norte capixaba .

Em termos demográficos, cerca de 80\% destes nove municípios apresentam menos de 30 mil habitantes, sendo o município de maior porte, Barra de São Francisco, detentor de menos de 45 mil moradores.

$\mathrm{Na}$ faixa intermediária desempenho, situaram-se, entre outros, Mantenópolis (noroeste), Marechal Floriano (sudoeste serrana), Iconha (litoral sul), Vila Valério (centro-oeste), Itarana 
(central Serrana), Marilândia (centro-oeste), São Roque do Canaã (centro-oeste), Aracruz (Rio Doce), Castelo (central-sul) e Itaguaçu (central-serrana), que registraram, respectivamente, do $3^{\circ}$ ao $12^{\circ}$ maiores Idebs capixabas em 2017, com notas entre 6,7 e 6,4.

Entre os municípios com evolução intermediária no Ideb do período analisado, aparecem ainda seis dos sete municípios da Região Metropolitana da Grande Vitória, a área mais rica e a de maior desenvolvimento do território capixaba. Nesse sentido, ressalta-se que esse dinamismo econômico não tem se convertido em indicadores educacionais de destaque, haja vista que estes municípios (Cariacica, Guarapari, Serra, Viana, Vila Velha e Vitória) registraram Idebs entre 5,4 e 5,8 em 2017.

Por outro lado, na faixa inferior de desempenho, Vila Pavão $(+0,13 \%)$, Afonso Cláudio (+0,15), Alfredo Chaves (+0,15\%), Fundão (+0,15\%), Domingos Martins (+0,16\%), Montanha $(+0,17 \%)$, Piúma $(+0,20)$, São Roque do Canaã $(+0,20 \%)$, Venda Nova do Imigrante $(+0,21 \%)$, Santa Teresa $(+0,22 \%)$, Ibatiba (0,22\%) e Divino de São Lourenço (+0,23\%) apresentaram as 12 menores evoluções percentuais do Ideb no período analisado, bem abaixo da média estadual. Neste último grupo, chama a atenção a presença de Vila Pavão, que dividiu com Águia Branca a liderança do Ideb, em 2017, ao registrar a nota 6,8.

Neste segundo conjunto, cinco municípios estão situados no centro do estado, quatro no sul, dois no norte e apenas um (Fundão) na Região Metropolitana da Grande Vitória.
A exemplo do primeiro conjunto, $80 \%$ dos municípios (10 de 12) detêm menos de 30 mil habitantes, sendo Afonso Cláudio (30.586 habitantes) e Domingos Martins (33.850 moradores) os de maior porte (IBGE, 2019).

Dessa forma, com base na tabela 1, conclui-se que 100\% dos 12 municípios que apresentaram as maiores evolucões percentuais do Ideb dos Anos Iniciais do Ensino Fundamental, no período analisado, e quase $100 \%$ dos que apresentaram as menores evoluções percentuais estão localizados no interior do estado, sendo a maioria deles muito pobres, de economia fortemente agropecuária e altamente dependentes das prefeituras.

Importante destacar, também, que maior evolução não significa maior Ideb, mas trajetória de maior avanço em relação às condições iniciais da rede de ensino. Dessa forma, a trajetória de evolução do Ideb das redes de ensino deve sempre ser relativizada, considerando que as redes com Idebs mais altos devem realizar um esforço menor de melhoria dos indicadores do que as redes com Idebs mais baixos. Assim, a compreensão da tabela 1 torna-se mais efetiva quando os Idebs alcançados pelas redes de ensino são comparados com as metas projetadas pelo Ministério da Educação (MEC). Como se pode perceber, as metas, mesmo para as redes de ensino com Idebs mais altos, são sempre projetadas com a finalidade de sustentação de uma trajetória de crescimento, ainda que comparativamente num ritmo menor.

Tabela 1 - Evolução do Ideb nos Anos Iniciais do Ensino Fundamental nos municípios capixabas (2013-2017).

\begin{tabular}{|c|c|c|c|c|c|c|c|c|c|c|c|c|}
\hline & \multicolumn{2}{|c|}{2007} & \multicolumn{2}{|c|}{2009} & \multicolumn{2}{|c|}{2011} & \multicolumn{2}{|c|}{2013} & \multicolumn{2}{|c|}{2015} & \multicolumn{2}{|c|}{2017} \\
\hline & $\begin{array}{l}\text { Alcan } \\
\text { çado }\end{array}$ & Meta & $\begin{array}{l}\text { Alcan- } \\
\text { cado }\end{array}$ & Meta & $\begin{array}{l}\text { Alcan } \\
\text { çado }\end{array}$ & Meta & $\begin{array}{l}\text { Alcan } \\
\text { çado }\end{array}$ & Meta & $\begin{array}{l}\text { Alcan } \\
\text { çado }\end{array}$ & Meta & $\begin{array}{l}\text { Alcan- } \\
\text { çado }\end{array}$ & Meta \\
\hline $\begin{array}{l}\text { Afonso } \\
\text { Cláudio }\end{array}$ & 5,5 & 4,7 & 5,9 & 5,1 & 6,7 & 5,4 & 6,3 & 5,7 & 6,1 & 6,0 & 6,3 & 6,2 \\
\hline $\begin{array}{l}\text { Água Doce } \\
\text { do Norte }\end{array}$ & 3,7 & 3,6 & 4,8 & 3,9 & 4,5 & 4,3 & 4,8 & 4,6 & 6,2 & 4,9 & 6,1 & 5,2 \\
\hline $\begin{array}{l}\text { Águia } \\
\text { Branca }\end{array}$ & 4,7 & 4,1 & 4,8 & 4,4 & 5,1 & 4,8 & 5,6 & 5,1 & 6,5 & 5,4 & 6,8 & 5,6 \\
\hline Alegre & 4,0 & 3,5 & 5,1 & 3,9 & 4,9 & 4,3 & 4,8 & 4,6 & 5,5 & 4,9 & 5,8 & 5,2 \\
\hline $\begin{array}{l}\text { Alfredo } \\
\text { Chaves }\end{array}$ & 5,5 & 4,7 & 5,9 & 5,1 & 6,7 & 5,4 & 6,3 & 5,7 & 6,1 & 6,0 & 6,3 & 6,2 \\
\hline $\begin{array}{l}\text { Alto Rio } \\
\text { Novo }\end{array}$ & 4,4 & 3,8 & 5,0 & 4,1 & 5,6 & 4,5 & 6,1 & 4,8 & 5,6 & 5,1 & 6,3 & 5,4 \\
\hline Anchieta & 4,1 & 4,2 & 5,1 & 4,6 & 5,2 & 5,0 & 5,2 & 5,3 & 5,5 & 5,5 & 6,0 & 5,8 \\
\hline Apiacá & 3,6 & 3,2 & 4,9 & 3,5 & 4,7 & 4,0 & 4,6 & 4,2 & 4,6 & 4,5 & 4,9 & 4,8 \\
\hline Aracruz & 4,7 & 4,7 & 5,6 & 5,0 & 5,8 & 5,4 & 5,9 & 5,6 & 6,0 & 5,9 & 6,4 & 6,1 \\
\hline $\begin{array}{c}\text { Atílio } \\
\text { Vixiáácqua }\end{array}$ & 3,8 & 4,0 & 4,4 & 4,3 & 4,2 & 4,7 & 5,7 & 5,0 & 5,2 & 5,3 & 5,6 & 5,6 \\
\hline $\begin{array}{c}\text { Baixo } \\
\text { Guandu }\end{array}$ & 4,3 & 4,0 & 5,1 & 4,3 & 5,1 & 4,7 & 5,4 & 5,0 & 5,5 & 5,3 & 5,8 & 5,5 \\
\hline $\begin{array}{l}\text { Barra de S. } \\
\text { Francisco }\end{array}$ & 4,0 & 3,8 & 4,4 & 4,1 & 4,9 & 4,6 & 5,4 & 4,8 & 5,6 & 5,1 & 5,9 & 5,4 \\
\hline
\end{tabular}




\begin{tabular}{|c|c|c|c|c|c|c|c|c|c|c|c|c|}
\hline $\begin{array}{c}\text { Boa } \\
\text { Esperanca }\end{array}$ & 4,2 & 3,1 & 4,7 & 3,4 & 5,1 & 3,9 & 5,5 & 4,1 & 5,5 & 4,4 & 5,9 & 4,7 \\
\hline $\begin{array}{c}\text { Bom Jesus } \\
\text { do Norte }\end{array}$ & 4,3 & 3,9 & 4,8 & 4,2 & 4,8 & 4,7 & 4,3 & 4,9 & 4,5 & 5,2 & 5,5 & 5,5 \\
\hline Brejetuba & 4,6 & 4,5 & 5,7 & 4,9 & 5,3 & 5,3 & 5,4 & 5,5 & 5,7 & 5,8 & 6,2 & 6,0 \\
\hline $\begin{array}{c}\text { Cachoeiro de } \\
\text { Itapemirim }\end{array}$ & 4,5 & 3,9 & 4,8 & 4,2 & 5,2 & 4,6 & 5,2 & 4,9 & 5,4 & 5,2 & 5,7 & 5,5 \\
\hline Cariacica & 4,1 & 3,9 & 4,5 & 4,2 & 4,6 & 4,6 & 4,9 & 4,9 & 5,3 & 5,2 & 5,4 & 5,5 \\
\hline Castelo & 4,8 & 4,8 & 5,3 & 5,2 & 5,7 & 5,5 & 5,9 & 5,8 & 6,1 & 6,0 & 6,4 & 6,3 \\
\hline Colatina & 4,7 & 4,4 & 5,3 & 4,8 & 5,7 & 5,2 & 5,7 & 5,4 & 5,8 & 5,7 & 6,0 & 6,0 \\
\hline $\begin{array}{c}\text { Conceição } \\
\text { da Barra }\end{array}$ & 4,3 & 3,5 & 4,5 & 3,8 & 5,4 & 4,3 & 5,2 & 4,5 & 5,5 & 4,8 & 6,0 & 5,1 \\
\hline $\begin{array}{l}\text { Conceição } \\
\text { do Castelo }\end{array}$ & 4,2 & 3,8 & 4,6 & 4,1 & 5,5 & 4,6 & 5,9 & 4,8 & 5,9 & 5,1 & 5,8 & 5,4 \\
\hline $\begin{array}{l}\text { Divino de S. } \\
\text { Lourenço }\end{array}$ & 4,0 & 3,6 & 4,1 & 4,0 & 4,6 & 4,4 & 4,8 & 4,7 & 5,0 & 5,0 & 4,9 & 5,2 \\
\hline $\begin{array}{l}\text { Domingos } \\
\text { Martins }\end{array}$ & 5,5 & 4,8 & 6 & 5,1 & 5,6 & 5,5 & 6,3 & 5,7 & 6,9 & 6,0 & 6,4 & 6,2 \\
\hline $\begin{array}{l}\text { Dores do } \\
\text { Rio Preto }\end{array}$ & 4,2 & 3,7 & 4,2 & 4,0 & 4,3 & 4,4 & 4,3 & 4,7 & 5,3 & 5,0 & 5,4 & 5,3 \\
\hline Ecoporanga & 3,9 & 3,6 & 4,6 & 4,0 & 4,6 & 4,4 & 5,6 & 4,7 & 6,0 & 5,0 & 5,8 & 5,3 \\
\hline Fundão & 4,7 & 4,4 & 4,5 & 4,7 & 5,0 & 5,1 & 4,8 & 5,4 & 5,4 & 5,6 & 5,4 & 5,9 \\
\hline $\begin{array}{l}\text { Governador } \\
\text { Lindenbera }\end{array}$ & 5,0 & 4,6 & 5,4 & 4,9 & 6,3 & 5,3 & 6,0 & 5,6 & 6,4 & 5,9 & 6,2 & 6,1 \\
\hline Guaçuí & 3,8 & 3,6 & 4,6 & 4,0 & 4,6 & 4,4 & 4,1 & 4,7 & 4,9 & 5,0 & 5,2 & 5,3 \\
\hline Guarapari & 4,2 & 3,8 & 4,6 & 4,2 & 4,9 & 4,6 & 5,0 & 4,9 & 5,4 & 5,2 & 5,8 & 5,4 \\
\hline Ibatiba & 4,5 & 3,8 & 4,6 & 4,1 & 4,8 & 4,6 & 5,0 & 4,8 & 5,0 & 5,1 & 5,5 & 5,4 \\
\hline Ibiraçu & 4,2 & 4,1 & 5,3 & 4,4 & 5,8 & 4,9 & 5,6 & 5,1 & 5,9 & 5,4 & 6,0 & 5,7 \\
\hline Ibitirama & 3,7 & 3,5 & 4,1 & 3,9 & 4,4 & 4,3 & 4,7 & 4,6 & 4,1 & 4,9 & 5,0 & 5,1 \\
\hline Iconha & 4,6 & 4,6 & 4,9 & 4,9 & 6,1 & 5,3 & 6,0 & 5,6 & 6,3 & 5,9 & 6,6 & 6,1 \\
\hline Irupi & 4,1 & 3,6 & 4,5 & 3,9 & 4,1 & 4,3 & 4,5 & 4,6 & 5,7 & 4,9 & 5,8 & 5,2 \\
\hline Itaguaçu & 5,1 & 5,1 & 6,1 & 5,4 & 5,6 & 5,8 & 6,5 & 6,0 & 6,5 & 6,3 & 6,4 & 6,5 \\
\hline Itapemirim & 3,8 & 3,5 & 4,5 & 3,8 & 4,7 & 4,2 & 4,7 & 4,5 & 5,1 & 4,8 & 5,6 & 5,1 \\
\hline Itarana & 5,0 & 4,8 & 6,6 & 5,1 & 5,8 & 5,5 & 5,6 & 5,8 & 5,9 & 6,0 & 6,5 & 6,3 \\
\hline lúna & 4,3 & 3,5 & 5,3 & 3,9 & 4,6 & 4,3 & 4,8 & 4,6 & 5,5 & 4,9 & 5,4 & 5,1 \\
\hline $\begin{array}{l}\text { Thiarecnal } \\
\text { Floriano }\end{array}$ & 4,8 & 4,6 & 5,1 & 4,9 & 5,4 & 5,3 & 5,9 & 5,6 & 6,3 & 5,8 & 6,7 & 6,1 \\
\hline Marilândia & 5,1 & 4,8 & 5,8 & 5,1 & 6,0 & 5,5 & 6,2 & 5,8 & 6,3 & 6,0 & 6,5 & 6,3 \\
\hline $\begin{array}{c}\text { Mimoso do } \\
\text { Sul }\end{array}$ & 4,0 & 3,7 & 4,4 & 4,0 & 4,5 & 4,4 & 5,0 & 4,7 & 5,5 & 5,0 & 5,8 & 5,3 \\
\hline Montanha & 4,7 & 3,3 & 4,6 & 3,7 & 5,5 & 4,1 & 5,4 & 4,4 & 5,3 & 4,6 & 5,5 & 4,9 \\
\hline Mucurici & 4,7 & 3,0 & 5,0 & 3,3 & 5,0 & 3,7 & 5,0 & 4,0 & 5,4 & 4,3 & 6,2 & 4,6 \\
\hline $\begin{array}{l}\text { Muniz } \\
\text { Freire }\end{array}$ & 4,2 & 3,8 & 5,0 & 4,1 & 5,2 & 4,5 & 5,3 & 4,8 & 5,7 & 5,1 & 5,8 & 5,4 \\
\hline Muqui & 4,0 & 3,6 & 5,0 & 3,9 & 5,0 & 4,3 & 5,3 & 4,6 & 5,7 & 4,9 & 5,6 & 5,2 \\
\hline $\begin{array}{c}\text { Nova } \\
\text { Venécia }\end{array}$ & 4,9 & 4,2 & 5,1 & 4,5 & 5,7 & 4,9 & 5,7 & 5,2 & 6,0 & 5,5 & 6,2 & 5,7 \\
\hline Pancas & 4,4 & 4,3 & 5,1 & 4,6 & 5,5 & 5,0 & 5,7 & 5,3 & 6,0 & 5,5 & 5,7 & 5,8 \\
\hline $\begin{array}{c}\text { Pedro } \\
\text { Canário }\end{array}$ & 3,7 & 3,5 & 4,4 & 3,9 & 5,0 & 4,3 & 5,0 & 4,6 & 5,5 & 4,8 & 5,7 & 5,1 \\
\hline Pinheiros & 4,3 & 3,8 & 4,9 & 4,2 & 5,2 & 4,6 & 5,5 & 4,9 & 5,7 & 5,1 & 5,9 & 5,4 \\
\hline Piúma & 4,5 & 4,2 & 4,6 & 4,5 & 5,3 & 4,9 & 5,4 & 5,2 & 5,0 & 5,4 & 5,4 & 5,7 \\
\hline Ponto Belo & 4,3 & 3,4 & 4,7 & 3,7 & 4,6 & 4,1 & 5,2 & 4,4 & 5,0 & 4,7 & 5,8 & 5,0 \\
\hline
\end{tabular}




\begin{tabular}{|c|c|c|c|c|c|c|c|c|c|c|c|c|}
\hline $\begin{array}{c}\text { Presidente } \\
\text { Kennedy }\end{array}$ & 3,9 & 3,2 & 3,2 & 3,6 & 4,6 & 4,0 & 5,6 & 4,3 & 6,4 & 4,5 & 5,9 & 4,8 \\
\hline $\begin{array}{c}\text { Rio } \\
\text { Bananal }\end{array}$ & 4,7 & 4,4 & 5,5 & 4,8 & 5,4 & 5,2 & 5,5 & 5,4 & 5,5 & 5,7 & 5,9 & 6,0 \\
\hline $\begin{array}{l}\text { Rio Novo } \\
\text { do Sul }\end{array}$ & 4,7 & 4,2 & 5,5 & 4,6 & 5,1 & 5,0 & 5,7 & 5,3 & 5,6 & 5,5 & 6,1 & 5,8 \\
\hline $\begin{array}{c}\text { Santa } \\
\text { Leopoldina } \\
\end{array}$ & 4,5 & 3,9 & 5,0 & 4,3 & 5,2 & 4,7 & 5,2 & 4,9 & 5,7 & 5,2 & 5,8 & 5,5 \\
\hline $\begin{array}{l}\text { Santa Maria } \\
\text { de Jetibá }\end{array}$ & 4,5 & 3,9 & 5,3 & 4,3 & 5,6 & 4,7 & 5,9 & 5,0 & 6,0 & 5,2 & 6,3 & 5,5 \\
\hline $\begin{array}{l}\text { Santa } \\
\text { Teresa }\end{array}$ & 5,0 & 4,4 & 4,9 & 4,8 & 5,5 & 5,2 & 5,8 & 5,4 & 6,3 & 5,7 & 6,1 & 6,0 \\
\hline $\begin{array}{l}\text { S. Domingos } \\
\text { do Norte }\end{array}$ & 4,2 & 4,2 & 4,8 & 4,5 & 4,8 & 4,9 & 4,7 & 5,2 & 5,7 & 5,5 & 5,8 & 5,7 \\
\hline $\begin{array}{c}\text { São Gabriel } \\
\text { da Palha }\end{array}$ & 4,4 & 4,1 & 5,1 & 4,4 & 5,6 & 4,8 & 5,9 & 5,1 & 6,0 & 5,4 & 6,3 & 5,6 \\
\hline $\begin{array}{c}\text { São José } \\
\text { do Calçado }\end{array}$ & 3,9 & 4,0 & 4,5 & 4,4 & 4,9 & 4,8 & 4,8 & 5,1 & 5,3 & 5,3 & 5,4 & 5,6 \\
\hline São Mateus & 4,2 & 3,8 & 4,7 & 4,2 & 5,2 & 4,6 & 5,4 & 4,9 & 5,6 & 5,2 & 5,5 & 5,4 \\
\hline $\begin{array}{l}\text { São Roque } \\
\text { do Canaã }\end{array}$ & 5,4 & 4,3 & 5,7 & 4,7 & 6,0 & 5,1 & 5,2 & 5,3 & 5,9 & 5,6 & 6,5 & 5,9 \\
\hline Serra & 4,2 & 3,6 & 4,6 & 3,9 & 4,8 & 4,4 & 4,7 & 4,6 & 5,3 & 4,9 & 5,6 & 5,2 \\
\hline Sooretama & 4,1 & 3,8 & 4,8 & 4,2 & 4,9 & 4,6 & 4,8 & 4,9 & 4,9 & 5,1 & 5,8 & 5,4 \\
\hline $\begin{array}{c}\text { Vargem } \\
\text { Alta }\end{array}$ & 4,6 & 3,9 & 5,5 & 4,2 & 5,3 & 4,7 & 5,7 & 4,9 & 6,3 & 5,2 & 6,0 & 5,5 \\
\hline $\begin{array}{l}\text { Venda Nova } \\
\text { do Imigrante }\end{array}$ & 5,2 & 4,7 & 5,6 & 5,0 & 5,9 & 5,4 & 6,0 & 5,6 & 6,0 & 5,9 & 6,3 & 6,1 \\
\hline Viana & 4,2 & 3,7 & 4,0 & 4,0 & 5,0 & 4,4 & 5,0 & 4,7 & 5,2 & 5,0 & 5,3 & 5,3 \\
\hline Vila Pavão & 6,0 & 4,3 & 4,9 & 4,6 & 5,9 & 5,0 & 6,2 & 5,3 & 5,8 & 5,6 & 6,8 & 5,8 \\
\hline Vila Valério & 5,2 & 4,0 & 5,5 & 4,4 & 5,7 & 4,8 & 6,1 & 5,1 & 6,0 & 5,3 & 6,6 & 5,6 \\
\hline Vila Velha & 4,4 & 4,1 & 5,0 & 4,4 & 4,9 & 4,8 & 5,1 & 5,1 & 5,3 & 5,4 & 5,6 & 5,6 \\
\hline Vitória & 4,2 & 4,1 & 4,8 & 4,4 & 4,9 & 4,8 & 5,0 & 5,1 & 5,6 & 5,4 & 5,6 & 5,7 \\
\hline $\begin{array}{c}\text { Espírito } \\
\text { Santo }\end{array}$ & 4,3 & 4,0 & 4,8 & 4,4 & 5,0 & 4,8 & 5,2 & 5,0 & 5,5 & 5,3 & 5,7 & 5,6 \\
\hline
\end{tabular}

Fonte: Inep.

Como se pode observar, Águia Branca $(6,8)$, Vila Pavão $(6,8)$, Mantenópolis $(6,7)$, Marechal Floriano $(6,7)$, Iconha $(6,6)$, Vila Valério $(6,6)$, Itarana $(6,5)$, Marilândia $(6,5)$, São Roque do Canaã $(6,5)$, Aracruz $(6,4)$, Castelo $(6,4)$, Domingos Martins $(6,4)$ e Itaguaçu $(6,4)$ apresentaram os 13 maiores Idebs nos anos iniciais do ensino fundamental do Espírito Santo em 2017, o último disponível, todos acima de 6,0, que corresponde à meta estabelecida pelo MEC até 2022 para todas as escolas e todas as redes de ensino do Brasil. Presidente Kennedy, município selecionado como foco deste trabalho, aparece na $37^{a}$ colocação, com Ideb de 5,9. Na avaliação anterior, em 2015, Kennedy havia registrado Ideb de 6,4 nos Anos Iniciais do Ensino Fundamental, nota que havia posicionado o município do litoral sul capixaba na $5^{\mathrm{a}}$ colocação entre os 78 municípios do Espírito Santo.

Por outro lado, como se pode perceber no gráfico 1, a seguir, os municípios que apresentaram os maiores Idebs em 2017 não coincidem com aqueles que apresentaram a maior evolução no período. Presidente Kennedy, um dos municípios que apresentou maior trajetória de evolução, não está posicionado entre os 13 maiores Idebs do estado. 


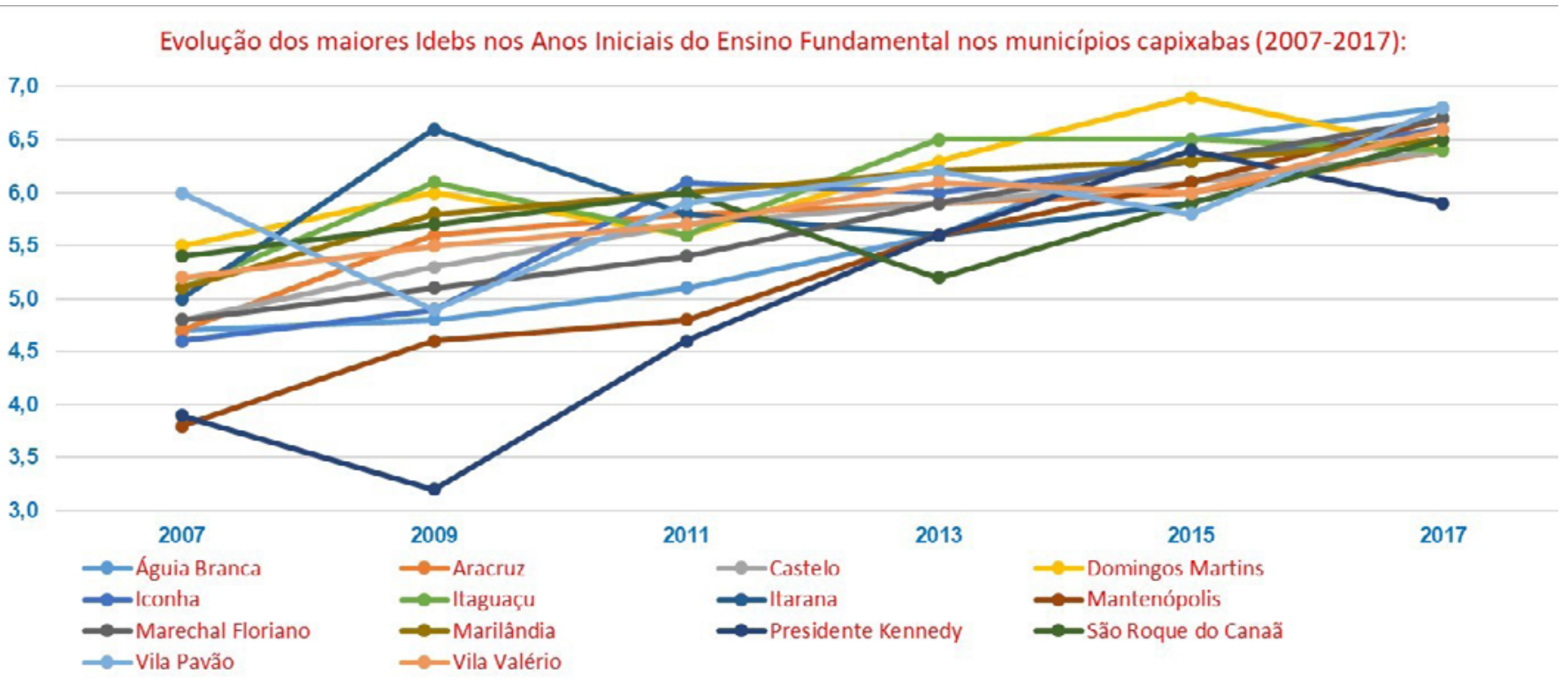

Fonte: Inep.

Em conjunto com a tabela 1, o gráfico 1 mostra que, após registrar uma queda de 0,7 pontos entre 2007 e 2009, o Ideb dos anos iniciais do ensino fundamental de Presidente Kennedy passou a apresentar uma trajetória de evolução crescente, saltando 14,0 pontos entre 2009 e 2011, 10,0 pontos entre 2011 e 2013 e 0,8 pontos entre 2013 e 2015. Neste último ano, o município passou a se posicionar na $5^{\mathrm{a}}$ colocação entre os 78 municípios do Espírito Santo. Em 2017, entretanto, houve a interrupção desta trajetória de evolução, com o recuo de 0,6 pontos no Ideb dos anos iniciais do ensino fundamental do município, significando uma queda de 32 posições no ranking dos 78 municípios do estado.

Perante este cenário, a seção a seguir, com base nos microdados do Inep, apresentará o resultado de uma investigação exploratória estatística, que buscou identificar as causas do declínio do desempenho, em 2017, do Ideb dos anos iniciais do ensino fundamental do município do litoral sul capixaba.

\section{0 desempenho de Presidente Kennedy}

Com população estimada, em 01 de julho de 2019, pelo Instituto Brasileiro de Geografia e Estatística (IBGE), em 11.574 habitantes (IBGE, 2019), e um território de 583,932 $\mathrm{km}^{2}$, Presidente Kennedy faz divisa, a sul, com o estado do Rio de Janeiro, limitando-se com os municípios fluminenses de Campos dos Goytacazes e São Francisco do
Itabapoana. A oeste, faz divisa com o município capixaba de Mimoso do Sul, limitando-se, ainda, com outros três municípios do Espírito Santo: Atílio Vivacqua, a noroeste, Itapemirim, a norte, e Marataízes, a oeste.

De acordo com o Censo Escolar (INEP, 2018), em 2018, Presidente Kennedy detinha 22 escolas no total, sendo 15 de ensino fundamental. A rede municipal possuía 14 escolas, nas quais 1.027 estudantes estavam matriculados nos anos iniciais do ensino fundamental ( $1^{\circ}$ ao $5^{\circ}$ anos). Em 2017, último ano de aplicação da Prova Brasil, 939 estudantes estavam matriculados nos anos iniciais do ensino fundamental na rede municipal (INEP, 2017).

Variando de 0 até 10, em que quanto mais próximo de 10, melhor, o indicador de aprendizado representa a proporção de alunos com aprendizado adequado em relação à própria etapa escolar, tomando como base os resultados da Prova Brasil. Como a Prova Brasil só avalia a proficiência em leitura e em resolução de problemas, o conceito de aprendizado adequado deste indicador só leva em consideração, na verdade, a proficiência dos estudantes em Língua Portuguesa e Matemática.

A classificação da escala de aprendizado (escala SAEB), porém, assim como o parâmetro de aprendizado adequado do indicador, varia de acordo com as disciplinas e com a etapa escolar. No caso dos anos iniciais do ensino fundamental, o aprendizado considerado avançado (além da expectativa, no qual se recomendam atividades desafia- 
doras) corresponde à pontuação igual ou superior a 250 na Prova Brasil, para Língua Portuguesa, e igual ou superior a 275 para Matemática.

Já o nível considerado proficiente (aquele no qual os estudantes atingem 0 aprendizado esperado, recomendando-se atividades de aprofundamento) corresponde à pontuação de 200 a 249, para Português, e de 225 a 274 para Matemática.

0 nível básico, já abaixo do parâmetro de proficiência, é representado pela pontuação entre 150 e 159 na Prova Brasil de Língua Portuguesa e entre 175 e 224 na Prova Brasil de Matemática. Para os estudantes situados neste estágio, o Inep recomenda a realização de atividades de reforço do aprendizado.

Por fim, o nível insuficiente é aquele com pontuação entre 0 e 149 em Português e entre 0 e 175 em Matemática. Para este nível, que concentra alunos com baixíssimo aprendizado, o Inep recomenda a recuperação de conteúdos.

Como se pode observar na tabela 2, acompanhando a evolução do indicador de aprendizado no período selecionado, a média da proficiência em Língua Portuguesa e em Matemática evoluiu continuamente entre 2011 e 2015, apresentando queda tanto em 2009 quanto em 2017. No caso de Português, a queda, em 2009, foi de 16,63 pontos e, em 2017, de 12,27. Em Matemática, foram perdidos 30,08 pontos em 2009, enquanto 2017 registou 19,10 pontos a menos que 2015. Ressalta-se, porém, que a recuperação tanto do aprendizado quanto das proficiências nas duas disciplinas em 2011 foi superior à queda registrada em 2009.

Tabela 2 - Evolução do Ideb desagregado dos Anos Iniciais do Ensino Fundamental do município de Presidente Kennedy-ES (2007-2017).

\begin{tabular}{|c|c|c|c|c|c|c|}
\hline & $\mathbf{2 0 0 7}$ & $\mathbf{2 0 0 9}$ & $\mathbf{2 0 1 1}$ & $\mathbf{2 0 1 3}$ & $\mathbf{2 0 1 5}$ & $\mathbf{2 0 1 7}$ \\
\hline Aprendizado & 4,57 & 3,69 & 4,86 & 5,95 & 6,89 & 6,31 \\
\hline Proficiência em Português & 159,71 & 143,08 & 180,11 & 211,94 & 230,76 & 218,49 \\
\hline Proficiência em Matemática & 193,95 & 163,87 & 189,63 & 216,69 & 248,02 & 228,92 \\
\hline Fluxo & 0,86 & 0,88 & 0,95 & 0,94 & 0,92 & 0,94 \\
\hline Ideb & 3,90 & 3,20 & 4,60 & 5,60 & 6,40 & 5,90 \\
\hline
\end{tabular}

Fonte: Inep.

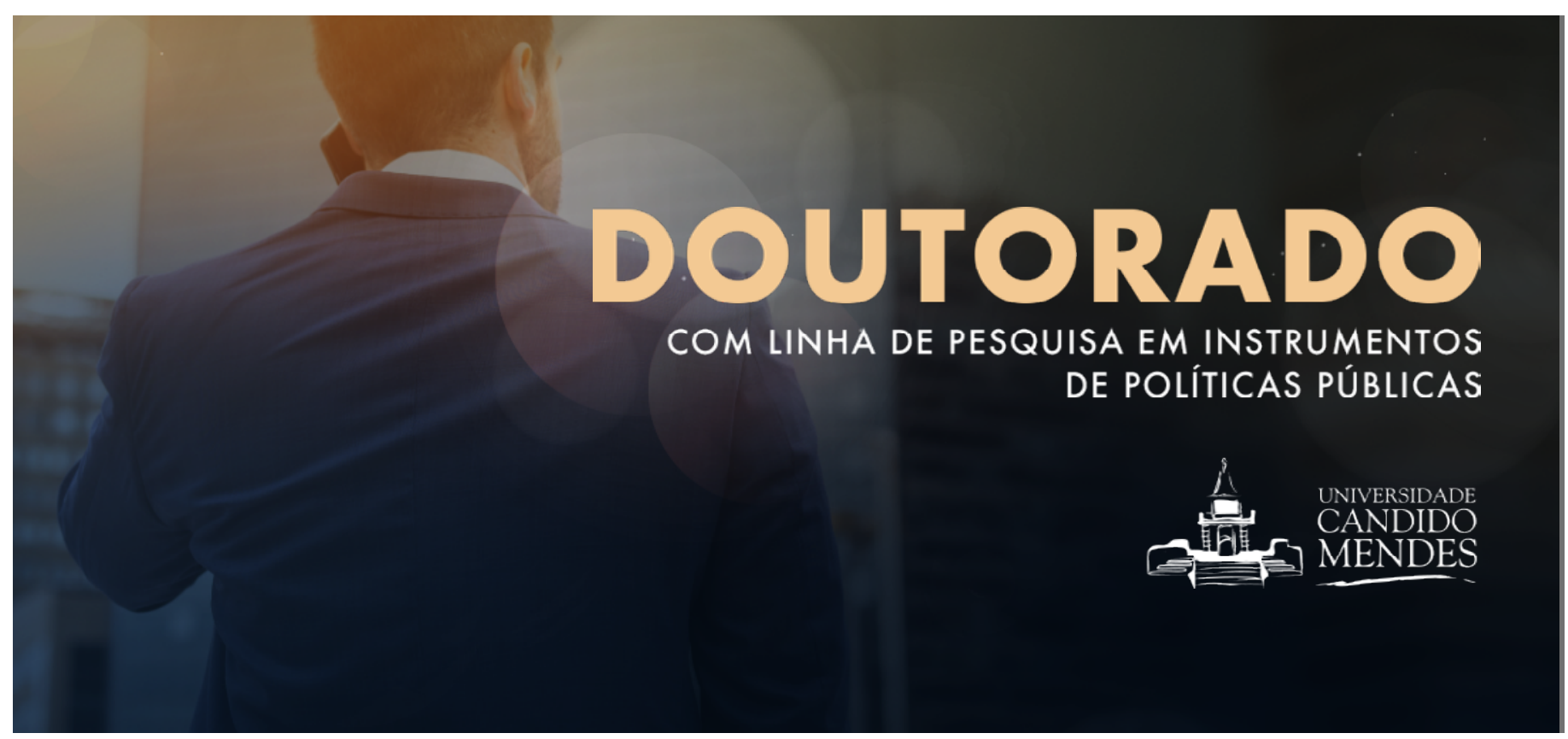


No que diz respeito à distribuição percentual, em 2015, $76 \%$ dos alunos do $5^{\circ}$ ano do ensino fundamental apresentaram proficiência em Leitura e Interpretação (Português) na Prova Brasil, isto é, alcançaram os níveis avançado e proficiente. Desse total, 30\% apresentaram nível avançado ou além da expectativa e $46 \%$, nível proficiente ou aprendizado esperado. 24\% apresentaram aprendizado básico ou pouco aprendizado e $0 \%$ apresentou aprendizado insuficiente ou quase nenhum aprendizado.

Em 2017, o total dos alunos do $5^{\circ}$ ano do ensino fundamental que apresentou proficiência em Português despencou para $57 \%$. Nesse universo, 18\% apresentaram nível avançado ou além da expectativa; 39\%, nível proficiente ou aprendizado esperado; $35 \%$, aprendizado básico ou pouco aprendizado; e $8 \%$, aprendizado insuficiente ou quase nenhum aprendizado.

Já em Resolução de Problemas (Matemática), 69\% dos estudantes do $5^{\circ}$ ano do ensino fundamental apresentaram proficiência na Prova Brasil em 2015. Desse total, $22 \%$ apresentaram nível avançado ou além da expectativa; $47 \%$, nível proficiente ou aprendizado esperado; $28 \%$, aprendizado básico ou pouco aprendizado; e 3\%, aprendizado insuficiente ou quase nenhum aprendizado.

Em 2017, o percentual dos estudantes do $5^{\circ}$ ano do ensino fundamental considerado proficiente em Matemática caiu para 54\%. Desse conjunto, $8 \%$ apresentaram nível avançado ou além da expectativa; $46 \%$, nível proficiente ou aprendizado esperado; 32\%, aprendizado básico ou pouco aprendizado; e 14\%, aprendizado insuficiente ou quase nenhum aprendizado.

A interpretação sobre esses dados, porém, ganha amplitude quando se considera o indicador de fluxo, composto pela combinação entre taxa de rendimento (aprovação, reprovação e abandono) e distorção idade-série (total de alunos com atraso escolar de dois anos ou mais). Como a taxa de rendimento é dada pelo Censo Escolar, realizado anualmente, para efeito de comparabilidade com o inter- valo do Ideb selecionado, sem abrir mão da atualização, apresentam-se, na tabela 5, os anos ímpares entre 2011 e 2017, acrescidos de 2018.

Ao se analisar a desagregação da taxa de rendimento, observa-se uma pequena evolução do percentual de aprovação entre 2011 e 2018, apesar da queda em 2013 e da recuperação somente a partir de 2017. Em síntese, em termos relativos, a cada dez alunos matriculados nos anos iniciais do ensino fundamental em Presidente Kennedy, seis conseguiram alcançar promoção para a série seguinte em 2018 (988 alunos num total de 1.028 matriculados).

Desse total, 99,5\% conseguiram aprovação no $1^{\circ}$ ano do ensino fundamental em 2018 (203 alunos); 100,0\%, no $2^{\circ}$ ano (187 aprovações); 91,3\%, no $3^{\circ}$ ano (202 aprovações); $96,5 \%$, no $4^{\circ}$ ano (196 aprovações); e $94,5 \%$, no $5^{\circ}$ ano (201 aprovações).

No que diz respeito ao percentual de abandono, ou evasão escolar, observa-se uma redução em termos gerais apesar da oscilação em 2017. Em 2018, o município conseguiu zerar o percentual de abandono nas suas escolas.

Já a reprovação, que acompanha no sentido oposto as taxas de aprovação, aumentou 0,2\% entre 2011 e 2018, tendo aumentado 2,4\%, entre 2011 e 2013, e 1,4\% entre 2013 e 2015. Entre 2015 e 2017, sofreu redução de 1,8\%, percentual de queda que se repetiu entre 2017 e 2018.

Neste último ano, 0,5\% obteve reprovação no $1^{\circ}$ ano do ensino fundamental (dois estudantes); $0,0 \%$, no $2^{\circ}$ ano (nenhum estudante); 8,7\% obtiveram no $3^{\circ}$ ano (20 estudantes); $3,5 \%$, no $4^{\circ}$ ano (oito estudantes); e 5,5\%, no $5^{\circ}$ ano (12 estudantes).

Como a distorção idade-série permaneceu praticamente constante durante todo o intervalo apresentado (entre 2013 e 2018, a cada 100 alunos matriculados, aproximadamente $16 \%$ estavam com atraso escolar de dois anos ou mais), o indicador de fluxo foi sensibilizado apenas pela oscilação das taxas de aprovação e reprovação. Assim, observa-se, na tabela 5, uma variação positiva de apenas 0,01 ponto no período 2011-2018. Entretanto, dentro do intervalo, houve uma suave queda até 2015 , quando retomou a trajetória de crescimento. 
Tabela 3 - Evolução das Taxa de Rendimento desagregada dos Anos Iniciais do Ensino

Fundamental do município de Presidente Kennedy-ES (2011-2017).

\begin{tabular}{|c|c|c|c|c|c|c|}
\hline & & $\mathbf{2 0 1 1}$ & $\mathbf{2 0 1 3}$ & $\mathbf{2 0 1 5}$ & $\mathbf{2 0 1 7}$ & $\mathbf{2 0 1 8}$ \\
\hline \multirow{2}{*}{ Aprovação } & Relativa & $95,5 \%$ & $93,3 \%$ & $92,2 \%$ & $93,9 \%$ & $96,2 \%$ \\
\cline { 2 - 7 } & Absoluta & 896 & 867 & 834 & 882 & 988 \\
\hline \multirow{2}{*}{ Abandono } & Relativa & $0,9 \%$ & $0,8 \%$ & $0,3 \%$ & $0,6 \%$ & $0,0 \%$ \\
\cline { 2 - 7 } & Absoluta & 09 & 08 & 03 & 06 & 00 \\
\hline \multirow{2}{*}{ Reprovação } & Relativa & $3,6 \%$ & $6,0 \%$ & $7,4 \%$ & $5,6 \%$ & $3,8 \%$ \\
\cline { 2 - 7 } & Absoluta & 34 & 56 & 68 & 53 & 40 \\
\hline Distorção idade-série & Total & $20 \%$ & $16 \%$ & $16 \%$ & $16 \%$ & $16 \%$ \\
\hline
\end{tabular}

Fonte: Inep.

Contudo, chama-se atenção para o fato de que, ao analisar os resultados das tabelas apresentadas, é fundamental considerar o total do universo dos estudantes que realizaram a Prova Brasil. Como a média da proficiência em Língua Portuguesa e Matemática no exame detém um peso muito elevado no cálculo do indicador, o total de estudantes que realiza a Prova Brasil pode influenciar no resultado, produzindo um efeito estatístico tanto a favor quanto em desfavor das escolas e redes de ensino.

A este respeito, destaca-se que, no caso de Presidente Kennedy, enquanto o ano de 2013, quando o município alcançou o Ideb de 5,6, registou 92\% de taxa de participação (do total de 105 alunos, 97 realizaram a Prova Brasil), segundo dados do Inep (2013; 2015; 2017), em 2015, quando o Ideb do município subiu para 6,4, a taxa de participação na Prova Brasil caiu para $82 \%$ (do total de 44 alunos, 36 realizaram o exame) e, em 2017, quando o Ideb do município caiu para 5,9, a taxa de participação registrada subiu para $98 \%$ (de 169 alunos, 165 realizaram a Prova Brasil).

Evidentemente que, por se tratar de uma avaliação censitária, a expectativa é a de que $100 \%$ dos estudantes das séries e escolas avaliadas realizem o exame. Entretanto, não se pode desconsiderar o efeito estatístico proveniente do total de alunos que efetivamente façam a prova. Até porque, na composição deste total, há o cruzamento entre as dimensões quantitativa e qualitativa. Como a Prova Brasil é uma avaliação direcionada às escolas públicas, que, por sua vez, se caracterizam pelo perfil bastante heterogêneo de sua clientela, quanto maior e mais próximo de 100\% o universo de participação no exame, mais heterogêneo se torna o desempenho dos estudantes, na me- dida em que aumenta a participação dos estudantes com menor aprendizagem. Como, em geral, especialmente no caso de clientelas mais heterogêneas, dentro da realidade das escolas públicas brasileiras, o total destes estudantes costuma superar o de alunos com melhor desempenho, a presença quantitativamente superior dos estudantes com menor aprendizagem tende a neutralizar o impacto da presença dos alunos com maior aprendizagem, contribuindo para a diminuição do resultado na Prova Brasil e, por reflexo, também no Ideb.

Como se pode deduzir do confronto entre os percentuais de participação na Prova Brasil e o resultado do Ideb, parte da melhora significativa apresentada por Presidente Kennedy em 2015, quando o município ganhou 0,8 ponto no Ideb em relação a 2013, atingindo o excelente resultado de 6,4, deve-se ao efeito estatístico derivado da redução do total absoluto de participação dos estudantes na Prova Brasil, de 97, em 2013, para 36 alunos, em 2015. Nesse sentido, pode-se inferir também que parte da redução do desempenho do município em 2017, quando registrou Ideb de 5,9, pode ser explicada pela ampliação do número de estudantes realizando a Prova Brasil, 165 naquele ano.

Entretanto, é importante destacar que, apesar do aumento significativo no total de participação, mesmo em relação a 2013, o Ideb de Kennedy em 2017, apesar da queda em relação a 2015, foi superior ao de quatro anos antes, o que pode sinalizar uma melhoria generalizada da aprendizagem no município, como consequência do impacto do crescimento do Ideb em 2015. Esta constatação, que pode vir a se constituir em hipótese de pesquisa, precisa de uma investigação detalhada, e fica como sugestão para estudos posteriores. 


\section{Considerações finais}

A Prefeitura de Presidente Kennedy atribui o salto de quase 30 posições no Ideb 2015, entre os municípios capixabas, à ampliação dos investimentos em educação a partir de 2013, fato que teria tornado o município o de maior investimento por aluno em todo o Espírito Santo (PREFEITURA DE PRESIDENTE KENNEDY, 2016). De acordo com o Anuário de Finanças dos Municípios Capixabas, publicado pela Aequus Consultoria, o município, até 2018, permaneceu na liderança do gasto por aluno em todo 0 estado, tendo investido, neste último ano, R\$ 26.186,04 com cada um dos seus 2.949 estudantes matriculados (BORGES; VILLELA, 2019). Tais investimentos, pelo que foi apurado pela pesquisa que gerou este artigo, só teriam sido possíveis pela aplicação à educação do município de parte significativa da arrecadação municipal de royalties e participações especiais recebidos pelo petróleo explorado na Bacia de Campos. Em 2019, de acordo com o Info Royalties (2020), esses recursos ultrapassaram o valor de RS 221 milhões.

Entre os investimentos destacados pela Prefeitura de Kennedy, que ajudariam a explicar o desempenho no Ideb 2015, estariam o aumento salarial de $57,3 \%$ dos professores da rede municipal em 2014, a reforma de 12 escolas, a inauguração de três creches e a oferta de cursos de pós-graduação, com o pagamento de bolsas de mestrado e doutorado para seus docentes (PREFEITURA DE PRESIDENTE KENNEDY, 2016). Entretanto, a pesquisa realizada apurou ainda como fatores relevantes e como diferencial da educação municipal de Presidente Kennedy a qualidade acima da média, em comparação com outras redes públicas de ensino, da infraestrutura das escolas, dos recursos pedagógicos, da merenda e do transporte escolar e dos programas de reforço de aprendizagem e de inclusão de alunos com necessidades especiais e altas habilidades.

Outros fatores que chamaram a atenção da pesquisa e que não costumam ser disponibilizados nas redes de ensino públicas brasileiras são 0 suporte às escolas oferecido por uma equipe multidisciplinar de saúde, formada, entre outros profissionais, por psicólogos, fonoaudiólogos e fisioterapeutas, e os investimentos na aplicação de um currículo sob a forma de sistema de ensino, semelhantemente ao adotado por muitas escolas particulares do pPaís, com o recebimento de materiais didáticos prontos e a aplicação de treinamentos para os professores.

De fato, o grau de qualificação e a prática do professor, em conjunto com os antecedentes familiares (formação acadêmica cultural e situação socioeconômica) e os estímulos durante a primeira infância (nutrição, saúde, vínculos socioemocionais e menor exposição à situação de estresse tóxico), são apontados pelo estudo, produzido em 2014 pelo Banco Mundial e considerado uma referência, "Professores excelentes: como melhorar a aprendizagem dos estudantes na América Latina e no Caribe" (BRUNS; LUQUE, 2014), como os principais fatores que impactam a aprendizagem.

Ao calcular o impacto da qualificação do professor na aprendizagem do estudante, o estudo conclui que os alunos com um professor mais fraco podem dominar $50 \%$ ou menos do currículo para uma dada série, enquanto alunos com um bom professor têm um ganho médio de um ano e estudantes com professores excelentes avançam 1,5 série ou mais (HANUSHEK, RIVKIN, 2010; ROCKOFF, 2004).

0 estudo mostra ainda que o contato com um único professor altamente eficaz aumenta as taxas de participação no ensino superior e a renda futura de um estudante, enquanto uma série de excelentes ou maus professores durante vários anos multiplica esses efeitos e pode levar a hiatos intransponíveis nos níveis de aprendizagem dos alunos (CHETTY, FRIEDMAN, 2014; ROCKOFF, 2004). Nesse sentido, o estudo conclui que nenhum outro atributo das escolas se aproxima desse impacto sobre o desempenho dos estudantes.

No caso do município de Presidente Kennedy, além da melhoria da remuneração e da qualificação dos professores, identifica-se a presença de, pelo menos, outras duas variáveis que podem ajudar a explicar o sucesso do desempenho do município no Ideb, especialmente em 2015: gasto público por aluno acima da média e oferta de infraestrutura e recursos pedagógicos adequados e meIhoria da remuneração e da qualificação dos professores.

A fim de consolidar a compreensão sobre as causas do sucesso de Presidente Kennedy, portanto, é preciso desenvolver estudos que avaliem o impacto do investimento público, do fornecimento de infraestrutura e recursos pedagógicos e da prática dos professores na aprendizagem dos estudantes. Estes estudos teriam como papel não apenas orientar a alocação dos investimentos do governo municipal, identificando os acertos e as ações que necessitam de correção de rumos, mas, sobretudo, avaliar e medir a possibilidade de replicação da política educacional adotada por Presidente Kennedy em outros municípios e, consequentemente, seu potencial de escala. 


\section{Referências}

BORGES, Alberto; VILLELA, Tânia (org.). Finanças dos Municípios Capixabas. Vitória: Aequus Consultoria, 2019. v. 25.

BRUNS, Barbara; LUQUE, Javier (org.). Professores excelentes: como melhorar a aprendizagem dos estudantes na América Latina e no Caribe. Washington, DC: Banco Mundial, 2014.

CHETTY, Raj; FRIEDMAN, John; ROCKOFF, Jonah. Measuring the Impacts of Teachers II: Teacher Value-Added and Student Outcomes in Adulthood. American Economic Review, Pittsburgh, PA, v. 104, n. 9, p. 2633-79, Sep. 2014.

HANUSHEK, Eric; RIVKIN, Steven. Generalizations about Using Value-Added Measures of Teacher Quality. American Economic Review, Pittsburgh, PA, v. 100, n. 2, p. 267-271, 2010.

IBGE - INSTITUTO BRASILEIRO DE GEOGRAFIA E ESTATÍSTICA. Estimativas de População em 01/07/2019. 2019. Disponível em: https://www.ibge. gov.br/ estatisticas/sociais/populacao/9103-estimativas-de-populacao.html?=\&amp\%252525 3Bt=downloads\&t=resultados. Acesso em: 20 nov. 2019.

INEP - INSTITUTO NACIONAL DE ESTUDOS E PESQUISAS EDUCACIONAIS ANÍSIO TEIXEIRA. Censo Escolar 2018. 2018. Disponível em: http://inep.gov. br/ microdados. Acesso em: 20 nov. 2019.

INEP - INSTITUTO NACIONAL DE ESTUDOS E PESQUISAS EDUCACIONAIS ANÍSIO TEIXEIRA. Censo Escolar 2011-2017. Disponível em: http://inep.gov. br/ microdados. Acesso em: 20 nov. 2019.

INEP - INSTITUTO NACIONAL DE ESTUDOS E PESQUISAS EDUCACIONAIS ANÍSIO TEIXEIRA. Ideb - Resultados e Metas: 2007-2017. Disponível em: http://ideb.inep.gov.br/. Acesso: em 20 out. 2019.

INEP - INSTITUTO NACIONAL DE ESTUDOS E PESQUISAS EDUCACIONAIS ANISIO TEIXEIRA. Nota Técnica $\mathbf{n}^{\mathbf{0}} \mathbf{1}$ : Índice de Desenvolvimento da Educação Básica - Ideb. [2007?]. Disponível em: http://download.inep.gov.br/educacao_basica/portal_ideb/ o_que_e_o_ideb/Nota_Tecnica_n1_concepcaolDEB.pdf. Acesso em: 20 nov. 2019.

INEP - INSTITUTO NACIONAL DE ESTUDOS E PESQUISAS EDUCACIONAIS ANÍSIO TEIXEIRA. Saeb (Aneb/Prova Brasil) 2015-2017. Disponível em: http://inep.gov.br/ microdados. Acesso em: 20 nov. 2019.

INEP - INSTITUTO NACIONAL DE ESTUDOS E PESQUISAS EDUCACIONAIS ANÍSIO TEIXEIRA. Saeb - Sistema de Avaliação da Educação Básica. 2019. Disponível em: http://portal.inep.gov.br/educacao-basica/saeb. Acesso em: 20 nov. 2019.

INFO ROYALTIES. Indicadores. 2020. Disponível em: https://inforoyalties.ucam-campos.br/. Acesso em: 13 jun. 2020.

PREFEITURA DE PRESIDENTE KENNEDY - ES. Educação de Kennedy é uma das melhores do Estado. 10 out. 2016. Disponível em: https://www.presidentekennedy.es.gov.br/noticia/ler/1331/educacao-de-kennedy-e-uma-das-melhores-do-estado. Acesso em: 25 nov. 2019.

ROCKOFF, Jonah. 2004. The Impact of Individual Teachers on Student Achievement: Evidence from Panel Data. American Economic Review, Pittsburgh, PA, v. 94, n. 2, p. 247-252, 2004. 